\title{
Subjective well-being in Swedish active seniors and its relationship with physical activity and commonly available biomarkers
}

This article was published in the following Dove Press journal:

Clinical Interventions in Aging

30 July 2014

Number of times this article has been viewed

\author{
Lovisa A Olsson ${ }^{1,2}$ \\ Anita Hurtig-Wennlöf ${ }^{2}$ \\ Torbjörn K Nilsson ${ }^{3}$ \\ 'Department of Laboratory Medicine/ \\ Clinical Chemistry, Örebro University \\ Hospital, ${ }^{2} \mathrm{School}$ of Health and \\ Medical Science, Örebro University, \\ Örebro; ${ }^{3}$ Department of Medical \\ Biosciences/Clinical Chemistry, Umeå \\ University, Umeå, Sweden
}

Background: Physical activity is claimed to be related to well-being and to a lower risk of cardiovascular disease. Therefore, the possible associations of well-being with physical activity and biomarkers of somatic health were studied in a sample of Swedish active seniors to determine the strength of these associations.

Methods: Three hundred and eighty-nine community-dwelling senior citizens (127 men and 262 women) of mean age $74 \pm 5$ years were recruited for this cross-sectional population study. Serum samples were analyzed for lipoproteins and markers of inflammation. The Psychological General Well-Being (PGWB) index was used to measure subjective well-being. Physical activity was assessed by the International Physical Activity Questionnaire modified for the elderly.

Results: More than $50 \%$ of men and women rated their physical activity as high; in the women, there was a significant difference between the age groups (younger and older than the median age $[$ median $=74.1$ years , respectively). The mean PGWB index indicates a high degree of subjective well-being in this group of Swedish seniors. Of the PGWB subdimensions, general health had the strongest positive relationship with physical activity $\left(r^{2}=5.4 \%\right)$. For the subdimensions of depressed mood, positive well-being, vitality, and PGWB index, physical activity had an $r^{2} \leq 4 \%$, while the contributions of sex, age, and biomarkers were minor.

Conclusion: We have estimated the contribution of physical activity to the variance of subjective well-being in active seniors. Physical activity appears to play a greater role as a determinant of subjective well-being than do biomarkers of somatic health, especially in females, but most of the variance remained unaccounted for by the studied variables.

Keywords: subjective well-being, physical activity, biomarkers

\section{Introduction}

The relationships between well-being, somatic health, and active aging, including physical activity, have been extensively studied and are associated with health benefits and reductions in mortality rates. ${ }^{1,2}$ The health benefits of physical activity are suggested to be mediated mainly by reduction of known risk factors, such as inflammatory factors and blood pressure, ${ }^{3}$ and are described in both apparently healthy populations ${ }^{4}$ and in groups with known cardiovascular disease. ${ }^{5}$

Regular physical activity in the elderly is related to well-being, ${ }^{6-9}$ and positive wellbeing has been associated independently with longevity in both healthy populations and in groups with already existing disease. ${ }^{10}$ Again, immune function is also suggested to be involved in the association between well-being and reduced mortality. ${ }^{11}$ Well-being is related to health and other personal and social characteristics in a complex way. ${ }^{12}$ One feature of well-being is subjective well-being, which is considered to contain three subdimensions, ie, life satisfaction, positive affect, and negative affect. ${ }^{7}$ In this study, the
Correspondence: Anita Hurtig-Wennlö School of Health and Medical Science, Örebro University, SE 70I 82 Örebro, Sweden

Tel +46 I930 I8I6

Email anita.hurtig-wennlof@oru.se 
revised World Health Organization charter of health promotion from $1986^{13}$ and the revised definition of subjective well-being: "An umbrella term for different valuations that people make regarding their lives, the events happening to them, their bodies and the circumstances in which they live" 14 serve as a point of departure. People evaluate conditions differently depending on their expectations, values, and previous experiences, ${ }^{15}$ and subjective well-being is the person's own evaluation of his or her life.

In contrast with subjective well-being, biomarkers are tools for objective diagnostics and for monitoring the course of a disease or a treatment, and have also been suggested to be useful as surrogate endpoints substituting for actual clinical outcomes. ${ }^{16}$ Biomarkers have also been launched in studies on well-being in efforts to increase our knowledge of the complex interplay between somatic processes and subjective well-being. ${ }^{17-19}$ Biomarkers such as C-reactive protein and interleukins have previously been found to have associations with subjective well-being. ${ }^{17,20}$

In this study of subjective well-being in active, elderly Swedish subjects, we hypothesized that subjective well-being would be accounted for by physical activity, possibly in interplay with biomarkers of inflammation, cardiovascular risk, metabolism, anthropometric data, and blood pressure. In the following, all these will be collectively referred to as biomarkers of somatic health. For any association found between subjective well-being, physical activity, and biomarkers of somatic health, the partial contribution of each covariate can then be estimated. Therefore, in this study, we investigated subjective well-being using the Psychological General Well-Being (PGWB) index, which measures six distress dimensions regarded as relevant to subjective wellbeing, ie, anxiety, depressed mood, positive well-being, selfcontrol, general health, and vitality. ${ }^{21}$ Physical activity was assessed by the International Physical Activity Questionnaire modified for the elderly (IPAQ-E). ${ }^{22}$

\section{Materials and methods}

Active seniors were recruited by a multiphase sampling procedure aimed at an elderly retired population living in various communities in central Sweden as previously described. ${ }^{23}$ Methods for anthropometry and blood pressure (automatic oscillometry) were as described elsewhere. ${ }^{23}$ Physical activity was assessed by a version of the IPAQ-E 22 based on the short version of the IPAQ (www. ipaq.ki.se) which measures physical activity during the previous week. The IPAQ-E has been previously validated. ${ }^{22}$ The categorical outcome from IPAQ-E assigns the subjects into one of three physical activity categories, ie, low, moderate, or high. Blood samples were taken with the subjects in the sitting position by venipuncture using vacuum tubes. Serum was obtained after clotting for 30-60 minutes at room temperature and centrifuging for 10 minutes at 2,000× $\mathrm{g}$. All samples were stored at $-70^{\circ} \mathrm{C}$ and analyzed as previously described..$^{23}$ The parameters measured in serum are enumerated in Table 1 and the procedures used have been previously described. ${ }^{23}$

The PGWB index, accessed from the MAPI Research Trust (www.mapi-trust.org), was used to measure subjective well-being or distress. ${ }^{21}$ The PGWB index consists of 22 items that reflect subjective well-being and distress during the past week. The PGWB index gives a maximum value of 132 (best subjective well-being) and a minimum of 22 (poorest subjective well-being). The Swedish version of the PGWB has been validated and reported previously. ${ }^{24}$

All subjects gave their specific and written informed consent to the present study, including genotyping and biobanking of the donated samples. The research ethics committees of Örebro County Council approved the study.

\section{Statistical analysis}

Statistical Package for the Social Sciences version 22.0 software was used for the statistical analysis (IBM Corp., Armonk, NY, USA). The biomarker and PGWB results are presented as the mean \pm standard deviation. In group comparisons with categorical variables, $\chi^{2}$ tests were used. Analyses of correlation coefficients were done using the Spearman correlation (rho). Cronbach's alpha coefficient was used to study the internal consistency of the PGWB instrument. After studying the residuals, some variables were subjected to natural logarithm transformation before statistical analyses were done. Comparisons between differences in mean values between groups were done using the two-samples $t$-test.

To study the relationship between subjective well-being, physical activity, and biomarkers, we performed general linear model analyses. Physical activity was entered as a fixed factor together with age and sex as independent variables into seven multivariate regression analyses with each of the six subdimensions and PGWB index as outcome variables. Body mass index (as an indicator of overweight or obesity) and high sensitivity C-reactive protein (a marker of inflammatory activity) were also entered in the model as covariates. Missing data were treated as described elsewhere. ${ }^{23}$

\section{Results}

The basic clinical and laboratory characteristics, physical activity levels, and PGWB results are shown in Table 1. 
Table I Basic and clinical characteristics, biomarker levels, physical activity, and results from the PGWB index in 389 active seniors

\begin{tabular}{|c|c|c|c|}
\hline & $\begin{array}{l}\text { Females } \\
n=262\end{array}$ & $\begin{array}{l}\text { Males } \\
n=127\end{array}$ & $P$-value \\
\hline Age, year & $73.8(6.9)$ & $74.4(6.4)$ & NS \\
\hline Body mass index, $\mathrm{kg} / \mathrm{m}^{2}$ & $26.0(4.1)$ & $26.2(3.5)$ & NS \\
\hline Systolic blood pressure, mmHg & $148(25.9)$ & $147(23.4)$ & NS \\
\hline Diastolic blood pressure, $\mathrm{mmHg}$ & $75.6(10.9)$ & $78.6(10.9)$ & $0.013^{*}$ \\
\hline Heart rate, beats/minute & $72(10.6)$ & $69(10.8)$ & $0.022^{*}$ \\
\hline High sensitivity C-reactive protein, mg/L $\mathrm{L}^{\ddagger}$ & $2.06(2.1)$ & $2.9(3.7)$ & NS \\
\hline High-density lipoprotein cholesterol, mmol/L & $1.75(0.39)$ & $\mathrm{I} .42(0.4 \mathrm{I})$ & $<0.001 * * *$ \\
\hline Low-density lipoprotein cholesterol, mmol/L & $3.6(0.92)$ & $3.4(0.97)$ & NS \\
\hline Apolipoprotein AI, g/L & $\mathrm{I} .70(0.267)$ & I.44 (0.293) & $<0.00 I^{* * *}$ \\
\hline Apolipoprotein B, g/L & $0.91(0.197)$ & $0.89(0.205)$ & NS \\
\hline Apolipoprotein B/apolipoprotein $\mathrm{Al}^{\ddagger}$ & $0.55(0.160)$ & $0.64(0.189)$ & $<0.00 \mathrm{I}^{* * *}$ \\
\hline \multicolumn{4}{|l|}{ Physical activity, IPAQ-E group (\%) } \\
\hline Low & 12.4 & 14.4 & NS \\
\hline Moderate & 32.2 & 34.8 & NS \\
\hline High & 55.4 & 50.8 & NS \\
\hline \multicolumn{4}{|l|}{ PGWB index } \\
\hline Anxiety (range 5-30) & $25.8(3.7)$ & $26.4(3.4)$ & NS \\
\hline Depressed mood (range 3-18) & $16.1(2.1)$ & $16.3(2.1)$ & NS \\
\hline Positive well-being (range 4-24) & $17.0(3.1)$ & $17.6(2.8)$ & NS \\
\hline Self-control (range 3-18) & I5.7 (2.I) & $16.2(1.9)$ & $0.036 *$ \\
\hline General health (range 3-18) & $15.2(2.6)$ & $14.7(3.0)$ & NS \\
\hline Vitality (range 4-24) & $18.5(3.3)$ & $18.7(3.2)$ & NS \\
\hline Index (range 22-132) & $108.3(13.7)$ & $109.8(13.4)$ & NS \\
\hline
\end{tabular}

Notes: Mean (standard deviation) or \% are shown. ¥Biomarkers were mathematically In-transformed before the two sample $t$-tests were computed; *significant at 0.05 level, ****significant at $0.00 \mathrm{I}$ level.

Abbreviations: IPAQ-E, International Physical Activity Questionnaire modified for the elderly; NS, not statistically significant; PGWB, Psychological General Well-Being.

Sex differences in the studied biomarkers are also displayed. As expected, the male participants had lower heart rate, serum high-density lipoprotein cholesterol, and apolipoprotein A-I (ApoA1) values, and a higher diastolic blood pressure and $\mathrm{ApoB} / \mathrm{A} 1$ ratio than the female participants. More than $50 \%$ of men and women rated their physical activity as high (374 [98.6\%] of the participants completed the IPAQ-E questionnaire).

The internal consistency (Cronbach's alpha coefficient) for the PGWB instrument was 0.93 for the PGWB index.
The women had a lower PGWB self-control score $(P=0.036)$ than the men, but there were no sex differences in the other subdimensions nor in the PGWB index.

Relationships between the PGWB results and the biomarkers were assessed by Spearman correlation (Table 2). Age was negatively related to all PGWB subdimensions and to the PGWB index (rho -0.050 to -0.162 ), with all relationships except for anxiety and self-control being statistically significant. Body mass index was negatively related to all PGWB subdimensions, as well as to PGWB index

Table 2 Spearman's rho for the bivariate correlations between the results of the six PGWB dimensions and the PGWB index versus age, BMI, systolic BP, HDL, LDL, ApoAI, ApoB, ApoB/AI, and CRP

\begin{tabular}{llllllllll}
\hline & Age & BMI & BP & HDL & LDL & ApoAI & ApoB & ApoB/AI & CRP \\
\hline PGWB subdimension & & & & & & & & & \\
$\quad$ Anxiety & -0.050 & -0.022 & 0.014 & -0.001 & 0.037 & -0.051 & -0.061 & -0.004 & 0.033 \\
Depressed mood & $-0.123^{* *}$ & -0.034 & -0.019 & 0.033 & 0.027 & 0.008 & -0.032 & -0.016 & 0.001 \\
Positive well-being & $-0.145^{* *}$ & -0.037 & -0.039 & 0.028 & 0.044 & 0.009 & 0.003 & 0.003 & -0.036 \\
Self control & -0.015 & -0.074 & -0.029 & 0.013 & -0.042 & -0.035 & -0.079 & -0.033 & 0.070 \\
General health & $-0.162^{* *}$ & $-0.207^{* * *}$ & -0.033 & $0.122^{*}$ & 0.031 & 0.055 & -0.013 & -0.033 & -0.070 \\
Vitality & $-0.110^{*}$ & $-0.157^{* *}$ & -0.016 & 0.054 & 0.059 & 0.026 & 0.011 & -0.013 & -0.055 \\
PGWB index & $-0.130^{*}$ & $-0.104^{*}$ & -0.017 & 0.050 & 0.037 & 0.013 & -0.031 & -0.020 & -0.029 \\
\hline
\end{tabular}

Notes: *Correlation is significant at the 0.05 level (two-tailed); **correlation is significant at the $0.0 \mathrm{I}$ level (two-tailed); ***correlation is significant at the $0.00 \mathrm{I}$ level (two-tailed). Abbreviations: ApoAI, apolipoprotein AI; ApoB, apolipoprotein B; ApoB/AI, the ratio between ApoB and ApoAI; BMI, body mass index; BP, blood pressure; CRP, C-reactive protein; HDL, high-density lipoprotein; LDL, low-density lipoprotein; PGWB, Psychological General Well-Being. 
Table 3 Spearman's rho for the bivariate correlations between physical activity as assessed by IPAQ-E (low, moderate, high) versus the results of the six PGWB dimensions and the PGWB index

\begin{tabular}{|c|c|c|c|c|c|c|c|}
\hline & Anxiety & $\begin{array}{l}\text { Depressed } \\
\text { mood }\end{array}$ & $\begin{array}{l}\text { Positive } \\
\text { well-being }\end{array}$ & $\begin{array}{l}\text { Self } \\
\text { control }\end{array}$ & $\begin{array}{l}\text { General } \\
\text { health }\end{array}$ & Vitality & Index \\
\hline \multicolumn{8}{|c|}{ Physical activity category } \\
\hline Sexes combined & 0.052 & $0.177 * *$ & $0.194 * *$ & $0.116 *$ & $0.246 * * *$ & $0.23 I^{* * * *}$ & $0.228 * * *$ \\
\hline Females & 0.061 & $0.220 * * *$ & $0.251 * * *$ & $0.155^{*}$ & $0.233^{* * * *}$ & $0.233^{* * * *}$ & $0.263^{* * *}$ \\
\hline Males & 0.043 & 0.095 & 0.094 & 0.042 & $0.27 \mathrm{I} * * *$ & $0.228 * * *$ & $0.165^{*}$ \\
\hline
\end{tabular}

Notes: *Correlation is significant at the 0.05 level (two-tailed); $* *$ correlation is significant at the 0.01 level (two-tailed); $* * *$ correlation is significant at the $0.00 \mathrm{I}$ level (two-tailed). Abbreviations: IPAQ-E, International Physical Activity Questionnaire modified for the elderly; PGWB, Psychological General Well-Being.

(rho -0.022 to -0.207 ), with general health, vitality, and PGWB index being statistically significant. Of the biomarkers, only one showed a statistically significant relationship with PGWB; high-density lipoprotein was positively related to general health (rho $=0.122 ; P<0.05)$.

Relations between physical activity and the PGWB results were assessed by Spearman correlation (Table 3). Analyzing all subjects (sexes combined) resulted in statistically significant associations for depressed mood, positive well-being, self-control, general health, vitality, and PGWB index (Rho 0.116-0.246), while there was no significant relationship between physical activity and the subdimension of anxiety. Separate correlation analyses in females and males, respectively, revealed stronger and more positive relationships between physical activity and PGWB in females than in males (Table 3 ).

To further study the relationship between subjective well-being, physical activity, and biomarkers, we performed general linear models considering different PGWB subdimensions as dependent variables, and physical activity, sex, age, body mass index, and high sensitivity C-reactive protein as independent variables (Table 4). Of the PGWB subdimensions, general health had the strongest relationship with physical activity $\left(r^{2}=5.4 \%\right)$, but sex and age $\left(r^{2}=7.2 \%\right)$ and body mass index $\left(r^{2}=9.4 \%\right)$ also contributed to well-being in this subdimension. For the subdimensions of depressed mood, positive well-being, vitality, and PGWB index, physical activity explained around 4\% of the variance, while sex, age, and biomarkers (ie, body mass index and high sensitivity C-reactive protein) had a minor contribution to the variance. The subdimensions of anxiety and self-control were unrelated to physical activity (not shown in Table 4).

\section{Discussion}

In elderly Swedish subjects living in their own homes and leading an active life, more than $50 \%$ of men and women assigned their physical activity in the high physical activity category of the IPAQ-E. This cohort showed a higher degree of subjective well-being (3\% higher PGWB index) when compared with data from a previous study performed in the general Swedish population. ${ }^{25}$ Full details of our study group as compared with the study in the general population have been published elsewhere. ${ }^{23}$

The importance of measuring biomarkers in studies of older people is based upon the assumption that they are objective indicators of health and functional decline in older age. ${ }^{26}$ We present, for the first time, a quantitative measure of the partial contribution of physical activity to the variance in subjective well-being. Our main finding was that physical activity accounted for a small but statistically significant fraction ( $5 \%$ or less) of PGWB scores in all subdimensions, with anxiety and self-control as conspicuous exceptions. On the other hand, biomarkers of somatic health, such as body composition, blood pressure, and inflammatory markers, contributed with an even smaller fraction of no more than $1 \%-2 \%$ to the variance in the PGWB index or its subdimensions.

Subjective well-being in old age depends on expectations regarding the ability to perform physical activity and of physical function. ${ }^{27}$ Lampinen et al found that well-being is associated with activity, better health, and mobility status. ${ }^{28}$ Garatachea et al also found that physical function and physical activity are associated with a feeling of subjective wellbeing. ${ }^{7}$ In a cohort of 151 men and women aged 60-98 years, the correlation coefficient between energy expenditure and subjective well-being was slightly higher than in our study. This positive effect of physical activity on well-being also applied in elders classified as dependent according to a daily activity index. ${ }^{7}$ We observed that the positive relationship between physical activity and subjective wellbeing was more consistent in women than in men (Table 3). To the best of our knowledge, such sex differences have not been described before.

Our findings of a positive relationship between physical activity and the PGWB index agree with the findings in a 
Table 4 Subjective well-being according to level of physical activity

\begin{tabular}{|c|c|c|c|c|c|}
\hline & & $\begin{array}{l}\text { Univariate } \\
\mathrm{n}(\text { model })=374\end{array}$ & $\begin{array}{l}\text { Model I } \\
\mathrm{n}(\text { model })=373\end{array}$ & $\begin{array}{l}\text { Model } 2 \\
n(\text { model })=371\end{array}$ & $\begin{array}{l}\text { Model } 3 \\
\mathrm{n}(\text { model })=364\end{array}$ \\
\hline \multicolumn{6}{|l|}{ Depressed mood } \\
\hline \multirow[t]{3}{*}{ Physical activity } & Low & $15.4 \pm 0.3$ & $15.5 \pm 0.3$ & $15.5 \pm 0.3$ & $15.4 \pm 0.3$ \\
\hline & Moderate & $16.0 \pm 0.2$ & $16.0 \pm 0.2$ & $16.0 \pm 0.2$ & $16.0 \pm 0.2$ \\
\hline & High & $16.6 \pm 0.1$ & $16.6 \pm 0.2$ & $16.6 \pm 0.2$ & $16.6 \pm 0.2$ \\
\hline$P$-value (physical activity) & & $<0.001$ & 0.002 & $<0.001$ & $<0.001$ \\
\hline$R^{2}$ adjusted (model) & & 0.038 & 0.045 & 0.045 & 0.040 \\
\hline \multicolumn{6}{|l|}{ Positive well-being } \\
\hline \multirow[t]{3}{*}{ Physical activity } & Low & $16.2 \pm 0.4$ & $16.5 \pm 0.4$ & $16.5 \pm 0.4$ & $16.6 \pm 0.4$ \\
\hline & Moderate & $17.0 \pm 0.3$ & $17.1 \pm 0.3$ & $17.1 \pm 0.3$ & $17.1 \pm 0.3$ \\
\hline & High & $17.7 \pm 0.2$ & $17.7 \pm 0.2$ & $17.7 \pm 0.2$ & $17.7 \pm 0.2$ \\
\hline$P$-value (physical activity) & & 0.002 & 0.020 & 0.015 & 0.021 \\
\hline$R^{2}$ adjusted (model) & & 0.027 & 0.036 & 0.037 & 0.031 \\
\hline \multicolumn{6}{|l|}{ General health } \\
\hline \multirow[t]{3}{*}{ Physical activity } & Low & $13.6 \pm 0.4$ & $13.7 \pm 0.4$ & $13.8 \pm 0.4$ & $13.7 \pm 0.4$ \\
\hline & Moderate & $14.8 \pm 0.2$ & $14.7 \pm 0.2$ & $14.7 \pm 0.2$ & $14.7 \pm 0.2$ \\
\hline & High & $15.6 \pm 0.2$ & $15.5 \pm 0.2$ & $15.6 \pm 0.2$ & $15.6 \pm 0.2$ \\
\hline P-value (physical activity) & & $<0.001$ & $<0.001$ & $<0.001$ & $<0.001$ \\
\hline$R^{2}$ adjusted (model) & & 0.054 & 0.072 & 0.094 & 0.093 \\
\hline \multicolumn{6}{|l|}{ Vitality } \\
\hline \multirow[t]{3}{*}{ Physical activity } & Low & $17.6 \pm 0.5$ & $17.7 \pm 0.5$ & $17.8 \pm 0.5$ & $17.8 \pm 0.5$ \\
\hline & Moderate & $18.1 \pm 0.3$ & $|8| \pm 0.3$. & $\mid 8.1 \pm 0.3$ & $18.1 \pm 0.3$ \\
\hline & High & $19.0 \pm 0.2$ & $19.3 \pm 0.2$ & $19.3 \pm 0.2$ & $19.3 \pm 0.2$ \\
\hline$P$-value (physical activity) & & $<0.001$ & $<0.001$ & $<0.001$ & $<0.001$ \\
\hline$R^{2}$ adjusted (model) & & 0.034 & 0.029 & 0.041 & 0.039 \\
\hline \multicolumn{6}{|l|}{ PGWB index } \\
\hline \multirow[t]{3}{*}{ Physical activity } & Low & $103.8 \pm 1.9$ & $104.6 \pm 2.0$ & $104.9 \pm 2.0$ & $104.8 \pm 2.0$ \\
\hline & Moderate & $107.4 \pm 1.2$ & $107.4 \pm 1.2$ & $107.4 \pm 1.2$ & $107.2 \pm 1.2$ \\
\hline & High & $111.6 \pm 0.9$ & $111.7 \pm 1.0$ & $\mid I 2.0 \pm 1.0$ & $\mid I 2.1 \pm 1.0$ \\
\hline$P$-value (physical activity) & & $<0.001$ & $<0.001$ & $<0.001$ & $<0.001$ \\
\hline$R^{2}$ adjusted (model) & & 0.039 & 0.037 & 0.043 & 0.042 \\
\hline
\end{tabular}

Notes: Physical activity was estimated by IPAQ-E score and grouped into three levels (low, moderate, high). Estimated marginal mean \pm standard error of the mean is shown for the PGWB dimensions and the PGWB index. Univariate analysis of variance was performed between the three levels of physical activity according to the IPAQ-E groups (low, moderate, high). Model I: IPAQ group + sex + age. Model 2: IPAQ group + sex + age + BMI. Model 3: IPAQ-E group + sex + age + BMI + hs-CRP.

Abbreviations: BMI, body mass index; hs-CRP, high sensitivity C-reactive protein; IPAQ-E, International Physical Activity Questionnaire modified for the elderly; PGWB, Psychological General Well-Being.

smaller cohort of participants of the Better Aging Project reported by Fox et al. ${ }^{6}$ In their study, physical activity was measured by accelerometry in a cohort of 176 subjects aged 70 years and over, and explained a similar fraction of the variance in subjective well-being as in our study. A difference is that they also found the anxiety subdimension to be related to physical activity, whereas in our study, both anxiety and self-control were unrelated to physical activity and to the studied biomarkers. In a review of physical activity and depression and anxiety disorders, Ströhle stresses that depression and anxiety-related symptoms often hinder physical activity, ${ }^{29}$ which could partly explain the different relationships between physical activity and the anxiety subdimension in the different studies.

The evidence for a role of physical activity in physical function is strong: maintenance of musculoskeletal fitness by physical activity will enhance the capacity to meet the demands of everyday life and allow a person to maintain functional independence for a longer period of time and prevent falls and fractures. ${ }^{30}$ Increased physical activity is also associated with reduced C-reactive protein levels $\mathrm{s}^{31}$ and increased high-density lipoprotein cholesterol levels ${ }^{32}$ with a dose-response pattern. A moderate level of physical activity (briefly described as about 30 minutes of walking per day) is suggested to decrease the relative risk of morbidity, mortality, and loss of independence by $30 \% .{ }^{33}$ Thirty minutes of daily physical activity is the general physical activity recommendation for older adults. This recommended level corresponds to the moderate category in the IPAQ-E, ${ }^{22}$ ie, the questionnaire used in this study.

The evidence for positive effects of physical activity on subjective well-being is growing as more intervention studies 
are conducted. ${ }^{29}$ Physical activity may be particularly important to well-being in older individuals, because it contributes to maintenance of physical function and thereby independent living. ${ }^{34}$ Groups with very low levels of physical activity are also reported to experience positive functional and psychological effects of physical activity. ${ }^{7}$ Furthermore, twin studies have reported better well-being in the more physically active twin of the twin pair. ${ }^{35}$

There are some limitations that should be considered in this study. We studied an accessible population, with probably better than average somatic health and somewhat better subjective well-being than a random age-matched population. ${ }^{25}$ Their level of physical activity is also probably higher than the average for their age group. We had no information about other factors that influence well-being, such as socioeconomic status, personality, educational level, and marital status. This limits the generalizability of our findings to the subgroup of what we have here termed "active seniors". Further, the cross-sectional design of our study prevents us from stating any causal relationship. In view of the rather low explanatory power of physical activity, and in particular of serum biomarkers, it is reasonable to assume that other factors, such as genetic predisposition to subjective well-being or ill health could also play a role, a possibility that should be addressed in future studies.

\section{Conclusion}

We have, for the first time, estimated the partial contribution of physical activity to the variance of subjective well-being in active seniors, weighed against the contribution of somatic health as estimated by commonly available biomarkers. We found that physical activity plays a significant positive, albeit minor, role in determining subjective well-being in active elderly subjects, whereas somatic health appears to play a subordinate role. Moreover, we identified a sex difference in the relationship between physical activity and subjective well-being, with females showing stronger positive relationships between physical activity and subjective well-being dimensions than males in this cross-sectional study of active seniors. These findings should be taken into account when planning future intervention studies using physical activity as a tool for improving subjective wellbeing in the elderly.

\section{Acknowledgment}

This work was supported by The Research Committee of Örebro County Council and Nyckelfonden, Örebro, Sweden.

\section{Disclosure}

None of the authors report any conflict of interest in this work.

\section{References}

1. Samitz G, Egger M, Zwahlen M. Domains of physical activity and allcause mortality: systematic review and dose-response meta-analysis of cohort studies. Int J Epidemiol. 2011;40:1382-1400.

2. Bellavia A, Bottai M, Wolk A, Orsini N. Physical activity and mortality in a prospective cohort of middle-aged and elderly men - a time perspective. Int J Behav Nutr Phys Act. 2013;10:94.

3. Hamer M, Sabia S, Batty GD, et al. Physical activity and inflammatory markers over 10 years: follow-up in men and women from the Whitehall II cohort study. Circulation. 2012;126:928-933.

4. Mora S, Cook N, Buring JE, Ridker PM, Lee IM. Physical activity and reduced risk of cardiovascular events: potential mediating mechanisms. Circulation. 2007;116:2110-2118.

5. Hamer M. Psychosocial stress and cardiovascular disease risk: the role of physical activity. Psychosom Med. 2012;74:896-903.

6. Fox KR, Stathi A, McKenna J, Davis MG. Physical activity and mental well-being in older people participating in the Better Ageing Project. Eur J Appl Physiol. 2007;100:591-602.

7. Garatachea N, Molinero O, Martinez-Garcia R, Jimenez-Jimenez R, Gonzalez-Gallego J, Marquez S. Feelings of well being in elderly people: relationship to physical activity and physical function. Arch Gerontol Geriatr. 2009;48:306-312.

8. McAuley E, Elavsky S, Jerome GJ, Konopack JF, Marquez DX. Physical activity-related well-being in older adults: social cognitive influences. Psychol Aging. 2005;20:295-302.

9. Ní Mhaoláin AM, Gallagher D, O Connell H, et al. Subjective well-being amongst community-dwelling elders: what determines satisfaction with life? Findings from the Dublin Healthy Aging Study. Int Psychogeriatr. 2012;24:316-323.

10. Chida Y, Steptoe A. Positive psychological well-being and mortality: a quantitative review of prospective observational studies. Psychosom Med. 2008;70:741-756.

11. Kiecolt-Glaser JK, Glaser R. Depression and immune function: central pathways to morbidity and mortality. $J$ Psychosom Res. 2002;53: 873-876.

12. Röysamb E, Tambs K, Reichborn-Kjennerud T, Neale MC, Harris JR. Happiness and health: environmental and genetic contributions to the relationship between subjective well-being, perceived health, and somatic illness. J Pers Soc Psychol. 2003;85:1136-1146.

13. World Health Organization. The Ottawa Charter for Health Promotion. 1986. Available from: http://www.who.int/healthpromotion/conferences/previous/ottawa/en/. Accessed May 31, 2014.

14. Diener E. Guidelines for national indicators of subjective well-being and ill-being. J Happiness Stud. 2006:397-404.

15. Inui TS. The need for an integrated biopsychosocial approach to research on successful aging. Ann Intern Med. 2003;139:391-394.

16. Lassere MN. The Biomarker-Surrogacy Evaluation Schema: a review of the biomarker-surrogate literature and a proposal for a criterion-based, quantitative, multidimensional hierarchical levels of evidence schema for evaluating the status of biomarkers as surrogate endpoints. Stat Methods Med Res. 2008;17:303-340.

17. Friedman EM, Hayney M, Love GD, Singer BH, Ryff CD. Plasma interleukin-6 and soluble IL-6 receptors are associated with psychological well-being in aging women. Health Psychol. 2007;26:305-313.

18. Seplaki CL, Goldman N, Weinstein M, Lin YH. How are biomarkers related to physical and mental well-being? J Gerontol A Biol Sci Med Sci. 2004;59:201-217.

19. Dockray S, Steptoe A. Positive affect and psychobiological processes. Neurosci Biobehav Rev. 2010;35:69-75.

20. Undén AL, Andreasson A, Elofsson S, et al. Inflammatory cytokines, behaviour and age as determinants of self-rated health in women. Clin Sci (Lond). 2007;112:363-373. 
21. Dupuy H. The Psychological General Well-Being (PGWB) index. In: Wenger NK, Mattson ME, Furberg CD, Elinson J, editors. Assessment of Quality of Life in Clinical Trials of Cardiovascular Therapies. New York, NY, USA: Le Jacq Pub; 1984.

22. Hurtig-Wennlöf A, Hagströmer M, Olsson LA. The International Physical Activity Questionnaire modified for the elderly: aspects of validity and feasibility. Public Health Nutr. 2010;13:1847-1854.

23. Olsson LA, Hagnelius NO, Olsson H, Nilsson TK. Subjective well-being in Swedish active seniors or seniors with cognitive complaints and its relation to commonly available biomarkers. Arch Gerontol Geriatr. 2013;56:303-308.

24. Wiklund I, Karlberg J. Evaluation of quality of life in clinical trials. Selecting quality-of-life measures. Control Clin Trials. 1991; 12(4 Suppl):204S-216S.

25. Dimenäs E, Carlsson G, Glise H, Israelsson B, Wiklund I. Relevance of norm values as part of the documentation of quality of life instruments for use in upper gastrointestinal disease. Scand J Gastroenterol Suppl. 1996;221:8-13.

26. Steptoe A. Psychosocial biomarker research: integrating social, emotional and economic factors into population studies of aging and health. Soc Cogn Affect Neurosci. 2010;6:226-233.

27. Sarkisian CA, Prohaska TR, Wong MD, Hirsch S, Mangione CM. The relationship between expectations for aging and physical activity among older adults. J Gen Intern Med. 2005;20:911-915.
28. Lampinen P, Heikkinen RL, Kauppinen M, Heikkinen E. Activity as a predictor of mental well-being among older adults. Aging Ment Health. 2006;10:454-466.

29. Ströhle A. Physical activity, exercise, depression and anxiety disorders. J Neural Transm. 2009;116:777-784.

30. Warburton DE, Nicol CW, Bredin SS. Health benefits of physical activity: the evidence. Can Med Assoc J. 2006;174:801-809.

31. Kasapis C, Thompson PD. The effects of physical activity on serum C-reactive protein and inflammatory markers: a systematic review. J Am Coll Cardiol. 2005;45:1563-1569.

32. Trejo-Gutierrez JF, Fletcher G. Impact of exercise on blood lipids and lipoproteins. J Clin Lipidol. 2007;1:175-181.

33. Paterson DH, Warburton DE. Physical activity and functional limitations in older adults: a systematic review related to Canada's Physical Activity Guidelines. Int J Behav Nutr Phys Act. 2010;7:38.

34. Frank JS, Patla AE. Balance and mobility challenges in older adults: implications for preserving community mobility. Am J Prev Med. 2003; 25:157-163.

35. Stubbe JH, de Moor MH, Boomsma DI, de Geus EJ. The association between exercise participation and well-being: a co-twin study. Prev Med. 2007;44:148-152.
Clinical Interventions in Aging

\section{Publish your work in this journal}

Clinical Interventions in Aging is an international, peer-reviewed journal focusing on evidence-based reports on the value or lack thereof of treatments intended to prevent or delay the onset of maladaptive correlates of aging in human beings. This journal is indexed on PubMed Central, MedLine,

\section{Dovepress}

CAS, Scopus and the Elsevier Bibliographic databases. The manuscript management system is completely online and includes a very quick and fair peer-review system, which is all easy to use. Visit http://www.dovepress. com/testimonials.php to read real quotes from published authors. 